\title{
A LEITURA EM UM CONTEXTO DE ENSINO DE LÍNGUA PORTUGUESA: UM CONVITE À REFLEXÃO
}

\author{
READING IN A PORTUGUESE LANGUAGE TEACHING CONTEXT: \\ AN INVITATION TO REFLECTION
}

\section{Letícia Veste Correia ${ }^{1}$ Patrícia Fabiana Bedran ${ }^{2}$}

\begin{abstract}
Resumo: O objetivo desta pesquisa é investigar as crenças acerca da leitura e das atividades de leitura em aulas de língua portuguesa, apresentadas por uma professora de uma escola da rede pública do ensino fundamental I, bem como promover uma discussão sobre os procedimentos do professor no que diz respeito ao trabalho com a leitura e as suas implicações para o processo de formação dos alunos. Trata-se de uma pesquisa qualitativa, de cunho etnográfico (ERICKSON, 1986; ANDRÉ, 2000), que apresenta como referencial teórico as pesquisas sobre crenças (BARCELOS, 2006; SILVA 2007), leitura e ensino (SOLÉ, 1998; KLEIMAN, 2001; SAVELI, 2003; SOARES, 2004) e formação reflexiva do professor (PIMENTA; GHEDIN, 2002 e ZEICHNER, 2008. Os resultados desta pesquisa evidenciam que a leitura em voz alta tinha lugar de destaque na sala de aula da professora investigada, que concebia leitura como oralização e como formação de hábito. Os dados obtidos permitiram instaurar uma discussão valiosa sobre a função da atividade de leitura em voz alta na sala de aula, bem como revelaram a necessidade de o professor tomar consciência sobre as crenças que direcionam sua prática pedagógica.
\end{abstract}

Palavras-Chave: leitura; formação do professor; crenças; prática reflexiva

Abstract: This research aims to investigate the beliefs regarding reading and reading activities, in Portuguese classes, introduced by an elementary school teacher as well as to promote discussion of the teacher's procedures concerning the use of reading and its implications for the development of students. This is a qualitative research, of ethnographic approach (ERICKSON, 1986 e ANDRÉ, 2000), having the teacher's studies on beliefs (BARCELOS, 2006; SILVA, 2007), reading and teaching (SOLÉ, 1998; KLEIMAN, 2001; SAVELI, 2003; SOARES, 2004) and reflexive development as theoretical reference (PIMENTA; GHEDIN, 2002; ZEICHNER, 2008). The results of this research demonstrate the reading aloud took prominence in the classroom of the investigated teacher who conceived reading as oralization and as habit

\footnotetext{
1 Graduada em Pedagogia - Licenciatura pela Universidade Estadual Paulista "Júlio de Mesquita Filho" UNESP/IBILCE. E-mail: leticia_veste@hotmail.com

2 Patrícia Fabiana Bedran é licenciada em Letras - Português e Italiano pela UNESP, câmpus de São José do Rio Preto. É mestre (2008) e doutora (2012) em Estudos Linguísticos, área de concentração Linguística Aplicada Ensino e Aprendizagem de Línguas, pela mencionada universidade. Foi bolsista Fapesp e realizou período de bolsa de doutorado sanduíche na Università Ca'Foscari, em Veneza - Itália. Atualmente, é professora assistente doutora do departamento de Educação da UNESP, câmpus de São José do Rio Preto, onde atua na área de Linguística Aplicada - Ensino de Língua Materna e na orientação e supervisão dos Estágios Curriculares Supervisionados em Língua Materna do Curso de Licenciatura em Letras. Realiza pesquisas sobre formação professores de língua, tendo como foco de interesse os seguintes temas: Crenças e Ensino de Língua; Emoções e Identidade; Comunidade de Prática e Tecnologia. E-mail: patbedran@gmail.com
} 
formation. The data obtained allowed for starting valuable discussion about the role of reading aloud in the classroom as well as revealed the necessary for the teacher to be aware of the beliefs which steer their pedagogical practices.

Keywords: reading; learning; teacher education; beliefs; reflexive practice.

\section{Introdução}

O homem acredita em alguma coisa desde o momento em que começou a pensar (BARCELOS, 2007). Tal fato tem servido de pressuposto e ponto de partida para os estudos sobre crenças no âmbito educacional, que cada vez mais vêm despertando o interesse de autores e pesquisadores como Barcelos (2004, 2006, 2007, 2011), Saveli (2003), Silva (2007), Woods (1996, 2003), Richardson (1996), Borg (2003), Dufva (2003). No entanto, apesar das diversas pesquisas na área, evidenciamos a escassez de estudos sobre crenças na área de língua portuguesa, especificamente aqueles voltados para a leitura nos anos iniciais do ensino fundamental, em que destacamos a relevância do trabalho de Saveli (2003). A necessidade de contemplarmos essa área de investigação, tendo em vista o contexto mencionado, bem com a relevância do trabalho com a leitura nesse período escolar, o qual pode tanto motivar e despertar o interesse dos alunos para que deem continuidade a essa atividade, quanto levá-los a um significativo desinteresse, logo nos primeiros anos de sua vida escolar, instigou-nos a realização desta pesquisa.

Diante da importância das crenças, entendidas como maneira de ver, perceber e compreender o mundo e seus fenômenos, que podem influenciar a prática do professor e, da mesma forma, serem influenciadas e modificadas pelas experiências vivenciadas por ele (Barcelos, 2003, apud BARCELOS, 2006, p.26) e da inquestionável necessidade do trabalho com a leitura e da leitura em sala de aula, conforme apontam estudiosos como Solé (1998), Soares (2004), Kleiman (2001, 2004) e Saveli (2003), e os documentos oficiais da área (BRASIL, 1997), justificamos a necessidade de se investigar, a partir do desenvolvimento de uma pesquisa qualitativa de cunho etnográfico (ERICKSON, 1986; ANDRÉ, 2000), as crenças sobre leitura e sobre o trabalho com a leitura, apresentadas por uma professora de uma escola da rede pública do ensino fundamental I, bem como promover uma discussão sobre os procedimentos do professor no que diz respeito ao trabalho com a leitura e as suas implicações para o processo de formação dos alunos.

Iniciaremos este artigo trazendo o referencial teórico que embasou este trabalho: Crenças (BARCELOS, 2004, 2006; BARCELOS; VEIRA-ABRAHÃO, 2006), Formação 
Reflexiva do professor (PIMENTA, 2002; ZEICHNER, 2008) e Leitura e ensino (SOLÉ, 1998; KLEIMAN, 2001; SAVELI, 2003; SOARES, 2004). Em seguida, após esboçarmos considerações sobre os participantes e o contexto da pesquisa, apresentamos a análise dos dados. Por fim, trazemos as considerações finais e as referências bibliográficas, na expectativa de que, com os resultados obtidos e com as discussões realizadas ao longo deste artigo, em âmbito teórico e prático, possamos colaborar com as pesquisas sobre crenças na área educacional e, consequentemente, trazer contribuições e reflexões para o ensino de língua portuguesa no que diz respeito principalmente ao trabalho com a leitura e à importância e conscientização das crenças sobre leitura apresentadas pelos professores.

\section{Crenças e formação reflexiva do professor}

Os estudos a respeito de crenças consolidam uma conceituada área de investigação na educação. Apesar das diversas pesquisas que foram e estão sendo realizadas (BARCELOS, 2004, 2006, 2007, 2011; KLEIMAN, 2001, 2004; SAVELI, 2003; SILVA, 2007; SOLÉ, 1998), verificamos a necessidade de uma atenção direcionada ao contexto de ensino de língua portuguesa, enquanto língua materna, já que grande parte dos estudos utiliza como objeto de investigação a língua estrangeira. E foi justamente por meio do intenso desenvolvimento e aprimoramento de pesquisas na área de língua estrangeira que surgiram os diversos termos para se referir às crenças e também suas diversas concepções, que contribuem como embasamento teórico pertinente para elaboração deste artigo.

Segundo Barcelos (2001, p.72 apud SILVA, 2007), a existência de vários termos para um mesmo conceito também acontece em outras áreas do conhecimento, mas ocorre principalmente em Linguística Aplicada, em que são encontrados termos como representações (RILEY, 1989; 1994), - teorias folclórico-linguísticas de aprendizagem (MILLER; GINSBERG, 1995), - cultura de aprender (ALMEIDA FILHO, 1993; CORTAZZI; JIN, 1996), - cultura de ensinar (ALMEIDA FILHO, 1993), - cultura de aprendizagem (RILEY, 1997), - concepções de aprendizagem e crença (BENSON; LOR, 1999), entre outras nomenclaturas. Dentre diversas concepções e nomenclaturas, ressaltamos a de Barcelos (2006), uma vez que compreendemos crenças como “(...) uma forma de pensamento, como construções da realidade, maneiras de ver e perceber o mundo e seus fenômenos, co-construídas em nossas experiências e resultantes de um processo interativo de interpretação e (re)significação (...)" (BARCELOS, 2006, p.18). 
Ao corroborarmos a definição de crenças trazida pela autora, ressaltamos suas características, imprescindíveis para a sua compreensão e para o desenvolvimento de pesquisas na área. De acordo com Barcelos (2006), algumas definições destacam mais a dimensão cultural e a natureza social das crenças. Nessa perspectiva, as crenças não são somente um conceito cognitivo, mas também social, porque surgem de nossas experiências e problemas, de nossa interação com o contexto e da nossa capacidade de refletir e pensar sobre o que nos cerca. As crenças são dinâmicas também porque são passíveis de mudanças ao longo do tempo e são motivadas por experiências práticas e teóricas. Além disso, podem ser paradoxais e contraditórias, uma vez que são capazes de agir como instrumento de empoderamento ou como obstáculos para o ensino e aprendizagem de línguas. Assim, segundo Barcelos (2006, p.20), as crenças são "sociais, mas também individuais e únicas; são compartilhadas, emocionais, diversas, mas também uniformes".

A partir de uma perspectiva da tradição hermenêutica, propõe-se uma relação entre as crenças de professores e suas ações de forma a considerar a complexidade dos contextos de ensino. De acordo com Richardson (1996, apud BARCELOS, 2006, p.25), os estudos, realizados com base nessa tradição, procuram "entender as complexidades dos contextos de ensino e dos processos de pensamento e das ações do professor dentro de seus contextos". Ao procurar entender essa relação de maneira contextualizada, é preciso observar a existência de duas possibilidades: o desencontro entre crenças e ações e a influência dos fatores contextuais.

Faz-se necessário, portanto, dispensar atenção a todos os fatores contextuais envolvidos nessa relação, bem considerar uma relação de influências múltiplas entre os fatores contextuais, crenças e ações. Ademais, de acordo com Barcelos (2004), torna-se fundamental, quando pensamos na formação e atuação prática do professor, criar oportunidade e espaço em sala de aula para alunos e, em especial, futuros professores, discutirem e se conscientizarem sobre suas próprias crenças e, posteriormente, sobre as crenças de seus alunos. Instigar essa prática é oportunizar aos professores uma formação mais crítica e reflexiva, que não deve estar pautada em juízo de valor, ou seja, em possíveis em julgamentos valorativos quando verificadas divergências entre crenças de alunos e professores.

É indiscutível que a conscientização do professor sobre suas próprias crenças e as crenças de terceiros só se torna viável quando a formação está pautada em uma prática mais reflexiva (SCHON, 1983; ZEICHNER, 2003, 2008) e menos tecnicista de ensinar. Uma educação que está voltada para uma postura crítica e reflexiva capacita professores a 
compreenderem e se conscientizarem acerca de seu próprio agir, enquanto professores, e, caso haja necessidade, (re)significarem-no, o que evidencia uma valoração da prática, apontada por Schön (1983), de forma que “(...) lhes possibilite [aos professores] responder às situações novas, nas situações de incerteza e indefinição" (PIMENTA, 2002, p.24).

Entendido por muitos pesquisadores como uma reação ao ensino técnico e uma desaprovação de programas que consideravam professores implementadores de teorias e ideias formuladas por pesquisadores (ZEICHNER; LISTON, 1996; ZEICHNER, 2003 apud PIMENTA; GHEDIN, 2002), o ensino reflexivo implica, portanto, em uma (re)significação do ensino e do papel do professor. Trata-se de valorizar o processo de produção docente a partir da prática. Por outro lado, deve-se ter um olhar atento a uma possível apropriação indiscriminada da prática docente e às concepções equivocadas advindas dessa nova perspectiva, como a supervalorização do professor como indivíduo, de forma a priorizar um certo individualismo quando o professor passa a acreditar que somente a experiência prática bastaria para o saber docente, dando origem a um 'praticismo', conforme aponta Pimenta (2002, p.26).

De acordo com Zeichner (2008), com a publicação do livro O profissional reflexivo de Schön (1983), o tema prática reflexiva passou a ter grande relevância na área. Posteriormente, de acordo com o autor, tornou-se um slogan adotado por formadores de educadores de diferentes perspectivas políticas e ideológicas para justificar o que faziam em seus programas e, depois de certo tempo, começou a perder qualquer significado específico (ZEICHNER, 2008, p.538). Apesar desse marco inicial na prática reflexiva e das contribuições advindas com essa publicação, tal reflexão apresentada por Schön (1983), de acordo com Liston; Zeichner (1993, apud PIMENTA, 2002), é limitada, uma vez que está associada a profissionais individuais que só conseguem efetuar mudanças imediatas, ou seja, não são capazes de alterar as situações além das salas de aula.

Para os autores, só a reflexão não seria suficiente - é preciso que o professor tenha capacidade de tomar atitudes objetivas para a redução dos problemas que enfrentará em sala de aula. Pautada em uma concepção mais crítica e social da prática reflexiva como forma de superar os problemas apresentados, Zeichner (1992, apud PIMENTA, 2002) pontua três perspectivas a serem acionadas em conjunto: a) a concepção de que a prática reflexiva deve centrar-se no exercício profissional dos docentes por eles mesmos e também nas condições sociais em que esta ocorre; b) o reconhecimento por parte dos professores de que seus atos são 
fundamentalmente políticos e que, portanto, podem se direcionar a objetivos democráticos emancipatórios e c) a ideia de que a prática reflexiva, enquanto prática social, só pode se realizar em coletivos, o que leva à necessidade de transformar as escolas em comunidades de aprendizagem nas quais os professores se apóiem e se estimulem mutuamente.

Dessa forma, entendemos que esses compromissos apresentam valores estratégicos que permitem criar as condições que levarão a mudanças institucionais e sociais, necessárias para a criação de uma sociedade mais justa, conforme aponta o autor:

\footnotetext{
Se, por um lado, as ações educativas dos professores, nas escolas, obviamente, não podem resolver os problemas da sociedade por elas mesmas, por outro, elas podem contribuir para a construção de sociedades mais justas e mais decentes. Os professores devem agir com uma clareza política maior sobre quais interesses estão sendo privilegiados por meio de suas ações cotidianas. Eles podem ser incapazes de mudar alguns aspectos da situação atual, mas ao menos estão conscientes do que está acontecendo (ZEICHNER, 2008, p.546).
}

A atuação condizente com uma postura reflexiva do professor em sala de aula só é possível quando a formação do professor é também realizada sob essa mesma perspectiva. A universidade como lugar direcionado ao ensino de técnicas para se ensinar deve ser (re)formulado para dar espaço à criação de um ambiente de reflexão importante para que o professor compreenda sua formação, seu processo de aprendizagem e seu trabalho enquanto docente. Assim sendo, o professor em formação necessita assumir um papel ativo, crítico, reflexivo diante de seu próprio processo de aprender e ensinar para que possa trabalhar sob essa mesma perspectiva formando também alunos críticos e reflexivos. E faz parte dessa educação a conscientização sobre sua própria compreensão, ou seja, é extremamente importante e desejável que o professor tenha consciência sobre suas crenças acerca do ensino, no que diz respeito ao seu papel, ao papel do aluno, ao papel do conteúdo que ensina e ao tipo de aluno que ele acredita e deseja formar. Tal conscientização é o primeiro passo para uma prática reflexiva e para possíveis (trans)formações.

\section{A Leitura em sala de aula: concepções e reflexões}

A leitura tem lugar de destaque nos livros didáticos, nos documentos oficiais (BRASIL, 1997) e nas pesquisas da área educacional. Segundo Coll e Martín (2004, apud LEAL; MELO, 2006), é considerada como um dos eixos principais a ser priorizado no Ensino Fundamental porque colabora para a construção da identidade cidadã do aluno, já que lhe permite o acesso a diferentes informações e a inserção em situações diversas da nossa sociedade letrada em que o 
texto escrito é utilizado para mediar as interações. E, quando pensamos na construção de uma identidade cidadã e na formação de um leitor crítico e reflexivo, isso necessariamente envolve uma concepção de leitura que vai além da decodificação, da oralização e/ou do mapeamento de informações em um dado texto.

Por outro lado, a escola, com a incumbência de ensinar a ler, tem interpretado tal tarefa de um modo um tanto quanto mecânico e formado alunos que, mesmo estando habilitado para essa prática, não se tornam necessariamente leitores. A maneira como a escola, mais necessariamente o professor, concebe e ensina a leitura, além de não contribuir com a capacidade leitora dos alunos, pode, em casos extremos, mas não distante da realidade educacional, ter efeito contrário e afastar as crianças de todo e qualquer tipo de leitura, conforme pontua Zilberman (2013) ao enfocar o trabalho com a literatura em sala de aula:

\begin{abstract}
A escola pode ou não ficar no meio do caminho: se cumprir sua tarefa de modo integral, transforma o indivíduo habilitado à leitura em um leitor; se não o fizer, arrisca-se a alcançar o efeito inverso, levando o aluno a afasta-se de qualquer leitura. Para evitar esse resultado, cabe entender o significado da leitura enquanto procedimento de apropriação da realidade, bem como o sentido do objeto através do qual ela se concretiza: a obra literária (ZILBERMAN, 2013, p. 221).
\end{abstract}

Para que a escola 'não fique no meio do caminho' e possa cumprir sua tarefa de maneira plausível no que se refere ao ensino da leitura, faz-se necessário que os professores apresentem embasamento teórico necessário e atualizado com relação à literatura da área para que possam refletir sobre procedimentos, práticas e atividades à luz da teoria. O embasamento teórico tornase, a nosso ver, conforme pontua Pimenta e Ghedin (2002), cultura objetivada na formação docente, atribuindo aos professores pontos de vistas diversificados para ações contextualizadas. Mas, tão importante quanto a teoria e a compreensão sobre seu papel e sua relação com a prática, é a conscientização sobre a concepção que se tem ou se assume sobre a leitura e sobre o trabalho com a leitura.

Neste trabalho, entendemos a leitura na perspectiva adotada por Solé (1998, p.23), que tem como embasamento Rumelhart (1977), Adams; Collins (1979), Alonso; Mateos (1985), Solé (1987), Colomer; Camps (1991). Para a autora, “(...) a leitura é o processo mediante o qual se compreende a língua escrita. Nesta compreensão intervêm tanto o texto, sua forma e conteúdo, como leitor, suas expectativas e conhecimentos prévios”. De acordo com a autora, torna-se fundamental o trabalho com as habilidades de decodificação e também o envolvimento do leitor em um "processo de previsão e inferência, que se apoia na informação proporcionada 
pelo texto e na nossa própria bagagem, em um processo que permita encontrar evidência ou rejeitar as previsões e inferências antes mencionadas" (p.23). Trata-se de conceber a leitura como um processo de interação entre o leitor e o texto, o que implica necessariamente na presença de um leitor ativo e um objetivo/finalidade para o ato de ler.

Assumir tal concepção de leitura envolve superar concepções mais tradicionais, como a da simples decodificação, conforme sugerem os Parâmetros Curriculares Nacionais - PCN (BRASIL, 1997), que apresentam uma proposta mais contextualizada, negociada e autônoma para o trabalho com a leitura. Ao assumir esse caráter reducionista e limitado que define o ato de ler, a escola vem produzindo leitores capazes de decodificar qualquer texto, mas que, por outro lado, apresentam grandes dificuldades para a compreensão do que tentam ler. Essa formação tem início com o processo de alfabetização, embora não se limite apenas a essa etapa de formação:

\begin{abstract}
O conhecimento atualmente disponível a respeito do processo de leitura indica que não se deve ensinar a ler por meio de práticas centradas na decodificação (...). É preciso que antecipem, que façam inferências a partir do contexto ou do conhecimento prévio que possuem, que verifiquem suas suposições - tanto em relação à escrita, propriamente, quanto ao significado. (...) Para aprender a ler, é preciso que o aluno se defronte com os escritos que utilizaria se soubesse mesmo ler - com os textos de verdade, portanto. (BRASIL, 1997, p.42)
\end{abstract}

Smith (1989, apud BREVES-FILHO, 1996) pontua que, aos poucos, os pesquisadores da linguagem começaram a conceituar a leitura como um processo, em que o leitor não depende basicamente de sua habilidade de decifrar sinais, mas sim de compreender e dar sentido a eles. Assim sendo, a oposição entre decodificação e compreensão não se sustentaria mais, dando espaço a uma relação imbricada entre ambas, que torna necessária e imprescindível ao bom leitor. Conforme explicitado no documento oficial, a leitura começa a ser entendida como um processo dinâmico de interação entre texto e leitor (aluno) e entre os próprios alunos e professores. Assim sendo, uma prática voltada para o ensino de estratégias de leitura, como estabelecimento de inferências, formulação de hipóteses de leitura, ativação do conhecimento prévio, dentre outras, torna-se imprescindível na e para a formação do bom leitor, ou melhor, na formação de um leitor crítico, reflexivo que negocia e constrói significado. 
Nessa construção de significado, ocupa lugar central, na prática do professor, o ensino e a conscientização das estratégias ${ }^{3}$ de leitura, que, para Solé (1998, p.60), não se trata de um fim em sim mesmo, mas um meio para que a criança possa interpretar o texto. Ademais, dialogando com o que foi exposto anteriormente, na leitura, significado e decodificação estarão necessariamente presentes, porém, com valores diferentes em diversas etapas. Como enfatiza a autora, para leitores experientes, as habilidades de decodificação tornaram-se automáticas e só são conscientes em algumas situações - um exemplo seria quando o leitor experiente encontra um texto manuscrito com uma letra tortuosa; já o leitor aprendiz, iniciante, necessita dessas habilidades com mais frequência em várias situações do seu cotidiano na busca do significado.

A lacuna na formação do profissional, que faz com que o professor não se volte para o desenvolvimento de uma prática adequada de trabalho com a leitura - soma-se a isso o fato de muitos professores não serem leitores, mas ensinarem os alunos a gostar de ler; a pobreza do material escrito com o qual o aluno entra em contato (dentro e fora da escola) e o lugar cada vez mais reduzido que a leitura ocupa no cotidiano do brasileiro contribuem e justificam as queixas dos alunos com relação às atividades de leitura realizadas em sala de aula Kleiman (2001). Acrescentamos às questões apontadas pela autora, a influência de avaliações externas, as quais são elaboradas com base em teorias e concepções sobre o que seja leitura, e acabam, em muitos contextos, tornando-se ponto central de referência para a elaboração de programas e desenvolvimento de práticas pedagógicas - o que e como ensinar - e para motivação da aprendizagem. Posto isso, trazemos como última questão, apontada por Kleiman (2001), o fato de que ninguém gosta de fazer aquilo que é difícil demais e nem aquilo que não apresenta sentido.

Para a maioria dos alunos, a leitura é considerada muito difícil, justamente porque não encontram sentido na realização desta atividade em sala de aula. Distante daquela leitura prazerosa, realizada em casa, no cantinho preferido, no aconchego do lar, e que permite, de acordo com a autora, fazer associações com as estórias lidas por seus cuidadores antes de dormir, encontramos o extremo oposto no ambiente escolar: o desenvolvimento de práticas descontextualizadas, desmotivadores e desprovidas de sentido para os alunos. Nessa perspectiva, Saveli (2003) acentua a existência de uma grande distância entre as teorias e as práticas de leitura desenvolvidas nas escolas, pois quase sempre a leitura é vista como uma

\footnotetext{
${ }^{3}$ Assumimos, neste trabalho, a concepção de estratégia adotada por Solé (1998, p.69-70): “(...) procedimentos de caráter elevado, que envolvem a presença de objetivos a serem realizados, o planejamento das ações que se desencadeiam para atingi-los, assim como sua avaliação e possível mudança".
} 
tradução oral do que está escrito. Essa concepção que considera um texto nele mesmo e por ele mesmo é muito comum. Há muita soletração e oralização e pouca leitura.

\section{Procedimentos e estratégias de leitura: breves considerações para e no âmbito educacional}

O ensino de estratégias de leitura torna-se inquestionável quando assumimos uma nova concepção de leitura (SOLÉ, 1998; KLEIMAN, 2001; GRANVILLE, 2008). Solé (1998) aborda, de maneira sistematizada, algumas diversas e necessárias estratégias que podem ser realizadas antes, durante e após o ato de ler, quando se tem como objetivo ajudar o aluno a compreender e construir sentido sobre aquilo que está lendo, prática que vai de encontro a uma avaliação da capacidade leitora, o que comumente ocorre em diversos contextos, quando o professor faz a verificação da leitura, seja ela por meio de questionamentos, de resumo ou de produção textual.

Seria desejável se houvesse a diferenciação por parte do professor de momentos em que se 'trabalha' a leitura e momentos em que apenas se 'lê'. Ambas são atividades importantes e deveriam constituir as práticas do professor, já que, na concepção da autora, "a leitura deve ser avaliada como instrumento de aprendizagem, informação e deleite" (SOLÉ, 1998, p.90). Tendo em vista a complexidade dessa atividade, seja ela utilizada para aprendizagem, informação e/ou deleite, o professor deve estar atento a sua complexidade e à capacidade que as crianças apresentam para responder a essa complexidade, pois, dessa forma, ele conseguirá oferecer ajuda aos alunos quando necessário, contribuindo para o enfrentamento dos desafios que envolvem a atividade de leitura.

$\mathrm{O}$ trabalho do professor deve ter início antes mesmo da leitura efetiva. $\mathrm{O}$ aluno precisa ser preparado para a leitura propriamente dita, não apenas para que haja motivação e interesse de sua parte, mas a fim de que a tarefa possa ser realizada com êxito, ou seja, de forma a auxiliar no processo de compreensão do texto. Solé (1998) elenca estratégias como: motivação do aluno, oferecimento e apresentação de objetivos de leitura, incentivo por meio de perguntas, realizações de previsões sobre o texto, entre outras. Tais estratégias servem para provocar a necessidade de ler e ajuda os alunos a descobrirem e compreenderem que a leitura apresenta diversas utilidades. Ademais, proporciona aos alunos os recursos necessários para que consigam enfrentar, com segurança, confiança e interesse, a atividade da leitura, além de auxiliar na transformação dos alunos em leitores ativos, ou seja, em leitores que sabem o porquê 
lêem e que são capazes de assumirem suas responsabilidades ante a leitura, como pontua a autora.

Importante considerar também que a leitura que não se manifesta de uma necessidade para chegar a um objetivo não é propriamente leitura. De acordo com Kleiman (2004b), nas diversas situações, em que, fora do ambiente escolar, recorremos à leitura, o fazemos com determinada finalidade. Na escola, isso não deveria ser diferente. Para a autora, sempre que lemos, lemos com determinado objetivo. Diante disto, seria desejável que o professor estivesse ciente da finalidade da leitura realizada e que conscientizasse seus alunos, tendo em vista a atividade programada - ler para obter uma informação precisa ou de caráter geral, seguir instruções, aprender, por prazer, para comunicar um texto a um auditório, verificar o que foi compreendido pelo aluno ou para praticar a leitura em voz alta.

Dentre essas diversas finalidades, destacamos a leitura como prática oral e a leitura para verificação do que foi aprendido, que tendem a ser priorizadas em sala de aula. Com relação à primeira, leitura em voz alta, merece destaque ainda mais intenso porque é realizada com exclusividade em muitos contextos. Nesse tipo de atividade, deseja-se que o aluno leia com clareza, rapidez, fluência, correção, pronúncia correta e respeito às normas de pontuação e ainda com entoação. Tudo isso são exigências que deixam a compreensão em um nível secundário, pois o principal objetivo da leitura passa a ser apenas a preocupação em respeitar tais exigências, conforme pontua Solé (1998) e Kleiman (2001).

No segundo tipo de leitura, de verificação, comumente espera-se que o aluno compreenda o texto para depois responder às questões. Porém, não se pode afirmar que, por meio da sucessão de perguntas e respostas, o aluno realmente terá compreendido de fato o texto, conforme pontua Solé (1998), pois tudo depende do trabalho do professor, do livro didático adotado e, principalmente, das questões formuladas, que, de acordo com Granville (2008), são geralmente óbvias, de mapeamento de informações no texto, que não exigem uma postura crítico-reflexiva e o estabelecimento de relações e inferências por parte do aluno leitor.

Também para Marcuschi (2005, p.51), que analisou questões de interpretação textual de livros didáticos de língua portuguesa, o problema estaria justamente na natureza dessa atividade e não em sua ausência: a compreensão como simples e natural atividade de decodificação de conteúdos inscritos de forma objetiva no texto ou simples cópia; uma mistura de outras tantas questões que não tem relação com o assunto; indagações genéricas que podem ser respondidas 
como qualquer dado e a sugestão de que compreender é 'identificar conteúdos', já que não promovem reflexões críticas.

Uma outra questão que merece relevância, identificada por Granville (2008), é a predominância da leitura informativa, ou seja, aquela que se volta para a aquisição de novos conhecimentos e/ou como aprendizagem de novos conceitos, que geralmente culmina em resolução de questões, em que não se trabalha as estratégias metacognitivas, reduzindo o processo de leitura à função simplesmente informativa. De acordo com a autora, estratégias metacognitivas são ações e procedimentos de leitura utilizados pelo leitor para resolver dificuldades impostas pelo texto, como exemplo as idas e voltas que o leitor faz para recuperar uma informação. Dessa forma, "[...] as estratégias metacognitivas ocorrem, portanto, na dimensão pessoal e cognitiva de cada um de nós, leitores, e são únicas e intransferíveis [...]" (GRANVILLE, 2008, p. 197). Nessa mesma perspectiva, Kleiman (2004b) afirma que é devido ao papel das estratégias metacognitivas na leitura que se pode confirmar que a leitura é um processo só, já que as diferentes maneiras de ler são somente vários caminhos para se chegar ao objetivo pretendido.

Condição primária para que possa haver aprendizagem, seria possibilitar aos alunos ver/assistir a um processo de leitura de forma a visualizar 'as estratégias em ação', conforme pontua Solé (1998, p.116). De acordo com a autora, para que os alunos compreendam e também usem compreendendo as estratégias, seria necessário realizar o que a autora denomina de leitura compartilhada que tem como principal objetivo ensinar a criança/leitora a compreender e a controlar sua compreensão. Tendo como fundamento uma perspectiva mais social (VYGOTSKY, 1987, 2010) de ensino, que prioriza o social como mecanismo fundamental para o desenvolvimento social e cognitivo, entendemos que esse processo de visualização das estratégias poderia ser (re)configurado para uma prática de (re)construção e negociação de estratégias, com participação colaborativa e efetiva dos alunos. Por meio de uma prática negociada, de construção, de direcionamento, se e quando necessário, em um processo de fornecimento de assistência, observando aquilo que o aluno já sabe e o que necessita saber, o professor trabalharia e conscientizaria os alunos sobre a importância de selecionar marcas e indicadores no texto, de formular hipóteses, de verificar hipóteses, de fazer inferências, de estabelecer relações entre as partes do texto etc.

Para Breves-Filho (1996, p.84), “[...] ensinar a ler requer não só ensinar um conjunto de estratégias, mas também criar uma atitude que faz da leitura a busca da coerência [...]”, pois, de 
acordo com Kleiman (1998), citada pelo autor, há necessidade, quando se lê e se ensina a ler, de se criar uma expectativa com relação ao referencial do texto, que auxilia no processo de compreensão, e isso precisa ser mostrado e ensinado para a criança; de avaliar-se durante o processo de leitura; de treinar o uso de diversas fontes de conhecimento - linguístico, discursivo e enciclopédicos - para que as falhas no processo de leitura possam ser resolvidas e, por fim, há a necessidade de perceber e entender o texto como unidade de sentido.

\section{Entendendo as crenças e os procedimentos acerca do trabalho com a leitura em um contexto de ensino de língua portuguesa no Ensino Fundamental I}

O contexto desta pesquisa são as aulas de língua portuguesa de uma sala de quinto ano do ensino fundamental I (anos iniciais) em uma escola regular da rede pública de ensino do interior paulista. Foram observadas, em novembro de 2014, oito aulas e, posteriormente, realizados oito diários reflexivos sobre as aulas observadas, com enfoque na prática do professor no que se refere ao trabalho com a leitura. A sala contava com vinte e nove alunos e uma professora denominada nesse estudo de Ana, nome fictício para preservar a identidade da participante. Além da observação e posterior reflexão, em diários, sobre prática da professora, foi feito um registro em áudio de uma aula em específico, que possibilitou observações mais detalhadas sobre a prática da professora, e também foi elaborado e aplicado um questionário aberto para a professora.

Realizamos uma leitura cuidadosa dos dados obtidos por meio da aplicação dos instrumentos, para verificação de palavras-chave, posteriormente organizamos as crenças em categorias e subcategorias, e, por fim, elaboramos as asserções devidamente exemplificadas. A partir da análise dos dados, que foram triangulados para garantir a confiabilidade dos resultados, verificamos que a professora Ana realiza um mesmo procedimento para trabalhar leitura em todas as aulas observadas: escolhe um aluno e solicita a ele a tarefa de pesquisar um gênero, determinado por ela e, na aula seguinte, de realizar a leitura em voz alta para a professora e para os demais colegas de sala. Em outros momentos, ela solicita a pesquisa para todos os alunos, sem seleção prévia, e, posteriormente, no momento de desenvolvimento da atividade de oralização, faz a indicação dos alunos que deverão realizar a leitura em voz alta e/ou permite que todos os alunos leiam, quando o tempo de aula reservado para a atividade é suficiente.

No excerto $1, \log$ a seguir, professora convida duas alunas, que fazem parte de uma minoria que realizou a tarefa - atividade de pesquisa do gênero fábula, a fazerem a leitura do 
texto em voz alta. Em seguida, no excerto 2, em aula posterior, podemos observar que a prática se repete, havendo apenas mudança de gênero - crônica, e todos os alunos, que fizeram a tarefa de pesquisar e trazer o gênero para a aula, são convocados para a leitura em voz alta.

\section{Excerto 1}

A professora perguntou quem trouxe a tarefa, a maioria não trouxe. Quase todos os dias a professora escolhe um aluno para trazer na próxima aula algum tipo de texto (o gênero é escolhido pela professora). Então, duas alunas trouxeram fábulas e fizeram a leitura em voz alta para a sala. (Diário -novembro de 2014).

\section{Excerto 2}

Em aula anterior foi solicitado para os alunos, como atividade extra-classe, a pesquisa sobre uma crônica ela apenas dita o gênero para os alunos. Na aula seguinte, os alunos trouxeram como tarefa, a crônica, então a professora foi escolhendo um aluno de cada vez para fazer a leitura em voz alta. (Diário -novembro de 2014).

Abordar a diversidade de textos e gêneros em sala de aula torna-se fundamental quando se deseja agir de forma a ultrapassar o trabalho com frases soltas e desvinculadas de um contexto, indo ao encontro de uma perspectiva do Letramento (SOARES, 2002; CARVALHO, 2008; ROJO, 2009). Em contrapartida, apenas a presença da diversidade textual em sala de aula não é suficiente - faz-se necessário trabalhar esses gêneros, o que significa abordá-los, de maneira efetiva e eficiente, explorando o que os distingue uns dos outros, ou seja, contemplar suas características como função sociocomunicativa, interlocutores, formas de circulação etc, conforme apontam Santos, Mendonça e Cavalcante (2006). Nessa mesma perspectiva, uma outra questão que precisa ser esclarecida é que o ensino de gênero textual não pressupõe necessariamente o ensino do texto e vice-versa. Ao se abordar as características do gênero textual, pode-se não oportunizar aos alunos, de acordo com os autores (p. 40), o conhecimento sobre o que dizem os textos, em outras palavras, "sabe-se apenas sobre como funciona o gênero, mas não se conhece o próprio texto". Da mesma forma, pode-se elaborar atividades de compreensão textual, sem que se explore características próprias dos textos pertencentes ao gênero apresentado.

O desejável seria que o professor tivesse conhecimento mais aprofundado dessas questões, ao propor um trabalho com texto em sala de aula, e, mais que isso, entendesse que se pode restringir o trabalho à abordagem do texto (conteúdo) ou do gênero textual, porém, devese ter em mente que as escolhas linguísticas do texto são resultados de uma restrição própria do gênero, assim sendo, as duas dimensões precisam estar articuladas. Como apontam as autoras, há necessidade de os alunos compreenderem os aspectos socioculturais (externos aos textos) e 
os linguísticos (internos ao texto) como fundamentais e indissociáveis para que se construa uma produção de sentido desejada por meio da linguagem. No caso, a atividade realizada pela professora - solicitação de textos para que os alunos leiam em voz alta - parece estar restrita apenas ao trabalho com o aspecto oral - entonação, pausa, melodia. Não há um trabalho de abordagem de conteúdo e/ou de gênero textual, de maneira articulada e/ou mesmo desarticulada.

Segundo Kleiman (2001), a prática de leitura em voz alta é justificada em muitos contextos porque possibilitaria ao professor perceber e verificar se o aluno está compreendendo ou não o que lê. Convergindo com tal justificativa, ao término de algumas dessas atividades, a professora questiona os alunos oralmente com relação ao que foi lido. São questões de compreensão textual que abarcam entendimento mais global do texto e aspectos mais pontuais, como por exemplo, a autoria da crônica, como podemos visualizar no excerto 3. É importante observar, por outro lado, que essa necessidade de verificação de compreensão da leitura não se dá de forma recorrente e acentuada, pois, conforme podemos verificar na realização de uma outra atividade de oralização, findada a leitura, Ana muda bruscamente de atividade - excerto 4.

\section{Excerto 3}

Professora: O que ficou comprovado nesse texto? Quem contou essa história? Quem escreveu? (...) Ah não colocou o autor né?! Olha, toda vez que a gente pega um texto de alguém, a gente tem que fazer a dedicatória a essa pessoa, tem que falar da onde foi tirado, quem foi que escreveu, isso é muito importante. (Gravação de áudio -novembro de 2014)

\section{Excerto 4}

Após os alunos realizarem a leitura das crônicas, a professora começou a revisão para o SAREMCA (avaliação externa), e não questionou os alunos sobre as crônicas. Ela simplesmente passou para outra atividade. (Diário - novembro de 2014)

Uma outra questão que merece evidencia é que, nessa prática, tendo em vista a oralização ser considerada como prática fundamental nas aulas de leitura, de acordo com o procedimento da professora, e os alunos serem responsáveis pela pesquisa de textos apresentados em sala, devemos considerar que talvez houvesse necessidade de o professor contribuir para a realização da busca textual pelos alunos, ou melhor, fornecer assistência necessária para a realização de pesquisas - abordar a questão da confiabilidade dos sites, utilização de fontes adequadas, no caso de pesquisas online, realizar visitas à biblioteca, de 
forma a explorar as obras presentes na biblioteca, entre outros. Ao definir o gênero, seria desejável que o professor fornecesse maiores instruções sobre a realização da pesquisa e sobre a atividade a ser realizada com o texto, de forma a preparar esses alunos para o desenvolvimento da tarefa.

Como a mediação não é realizada antes do desenvolvimento do ato de leitura, o aluno parece cumprir a atividade de forma mecânica, ou seja, faz a tarefa porque foi solicitada pelo professor, sem ter maior conhecimento sobre o objetivo, a forma de proceder e sem que haja reflexão sobre as contribuições dessa atividade, que apresenta como finalidade a realização da leitura em voz alta. Ademais, se pensarmos que o objetivo não é trabalhar o conteúdo e/ou o gênero textual, mas apenas a oralização, poderíamos pensar que há necessidade também de auxiliar esses alunos no desenvolvimento de processo - talvez solicitando uma leitura silenciosa, à priori, com a mediação do professor, ou por meio da utilização de outras estratégias e recursos, com o intuito de auxiliá-los em suas possíveis dificuldades para que a exposição oral em público ocorra da melhor forma possível, sem constrangimentos ou grandes transtornos.

Ao mapear e buscar compreender, a partir do desenvolvimento de sua pesquisa, as crenças de leitura, apresentadas por professoras que atuavam na Educação Infantil e no Ensino Fundamental I, Saveli (2003) também detectou momentos de leitura em que a suposição das professoras é que o ato de ler se confunde com o de oralizar, ou seja, em que se lê para provar que se sabe ler. Ao realizar essa prática, qualquer criança, ou até mesmo o leitor mais experiente, poderá temer a leitura em voz alta e ler incorretamente. Além disso, a autora observou que as professoras podem não perceber que o desinteresse da criança pela leitura pode estar mais associado às propostas ou ao material de leitura que ela está tendo acesso do que precisamente às dificuldades individuais que encontra no ato de ler.

$\mathrm{O}$ excerto a seguir explicita essa falta de motivação da aluna que é chamada para fazer a leitura. Apesar de não percebê-la como atividade prazerosa e apresentar resistência à priori, a aluna Maria atende ao pedido da professora.

\section{Excerto 5}

Professora: Quem mais trouxe mesmo? (Professora faz referência ao texto solicitado)

Aluno: A Maria tia!

Professora: Maria leia então.

Maria: Aaaah tia!! (Aluna demonstra por meio de gestos e entonação da frase que não deseja ler, mas posteriormente realiza a leitura) (Gravação de áudio - novembro de 2014) 
Assim como Kleiman (2001), entendemos que a restrição das aulas de leitura apenas ao desenvolvimento dessa forma de aprendizagem, realizada por meio da oralização, pode ser ineficaz, dependendo do leitor que desejamos formar. Quando essa prática de leitura torna-se frequente e prioritária, e até mesmo exclusiva em sala de aula, pode desencadear uma lacuna na formação do leitor, que em sua grande maioria não chega ao nível da compreensão do texto. Na contra mão desse objetivo, a leitura em voz alta pode até mesmo dificultar essa compreensão desejada, como afirma a autora, uma vez que há uma preocupação do aluno e do professor com relação à entonação, ao ritmo da leitura, à pontuação, entre outros aspectos, em detrimento do conteúdo do texto.

Por outro lado, não podemos perder de vista que os aspectos formais necessitam ser trabalhados pelo professor e a oralização torna-se o único caminho. Tem-se, assim, uma necessidade real de trabalho com a leitura oral, que não pode ser justificada por uma prática pautada e direcionada por conhecimentos e compreensões equivocadas sobre as habilidades e competências desenvolvidas e avaliadas com a realização desse tipo de leitura - aprendizagem da forma não pode ser sinônimo de compreensão de conteúdo. Ademais, torna-se fundamental um olhar mais acurado e consciente sobre os procedimentos de ensino utilizados pelo professor durante o trabalho com a oralização. Nesse sentido, práticas avaliativas, em que se pode verificar uma exposição do aluno, sem que haja o devido preparo para o desenvolvimento da tarefa, de forma a não formar o leitor para este tipo de atividade, necessitam ser revistas.

Neste contexto de realização da pesquisa, uma explicação plausível, que possivelmente justifica a recorrência diária desse tipo de atividade de oralização de gêneros diversos, é a crença de que o processo de leitura se dá por meio da formação de hábito e de que correspondem às atribuições do professor solicitar a pesquisa de textos diversos, instigar a leitura diária de textos em sala e contemplar uma diversidade textual para, assim, estimular o aluno a gostar de um segmento textual. Tais concepções podem ser observadas por meio das atividades práticas realizadas por Ana e por meio de seu discurso, ao ser questionada sobre como compreende o processo de leitura (excerto 6) e sobre qual seria o papel do professor no que diz respeito ao trabalho com a leitura em sala de aula (excerto 7).

\section{Excerto 6}

O processo de leitura é adquirido muitas das vezes por se fazer o hábito de ler. (Questionário - novembro de 2014)

\section{Excerto 7}


O professor deve fazer a leitura diariamente em sala e estimular os alunos a buscar novos textos (...) deve estimular os alunos fazendo com que [o aluno] goste de algum segmento textual, trazendo pra sala de aula diversos gêneros textuais. (Questionário - novembro de 2014)

De acordo com Breves-Filho (1996, p.84), muitos professores tendem a trabalhar e defender a necessidade de o aluno criar o 'hábito' da leitura, esquecendo ou não se atentando para o fato de que a formação de hábitos é realizada por meio de um processo mecânico, repetitivo, que vai na contramão da preocupação com a construção de sentidos e com a atividade prazerosa que Kleiman (2001) faz menção quando realizada no aconchego do lar. A atividade sem propósito de leitura e de formação do leitor claramente definidos, realizada de maneira mecânica, repetitiva e avaliativa, pode contribuir com a desmotivação do aluno, como podemos observar no excerto 5 - Maria não se sente motivada para fazer a leitura e sinaliza isso para a professora e os demais alunos, por meio de gestos e entonação.

Essa forma de realizar a atividade não ensina ou avalia a capacidade de compreensão textual por parte dos alunos, podendo, ao contrário, dificultar a capacidade e a utilização de estratégias para se entender o texto, já que os alunos estão preocupados, no momento de realização da leitura, com os aspectos formais e não se atém ao conteúdo do texto (KLEIMAN, 2001). Conforme abordamos anteriormente, entendemos que a(s) leitura(s), em situações além do contexto escolar, são realizadas tendo em vista objetivos/finalidades diversas, o que, consequentemente, deveria dar origem a atividades e práticas diversas de leitura em sala de aula (SOLÉ, 1998), as quais tendem a ser menos ou mais motivadoras. A prática de leitura em voz alta, por exemplo, deveria sempre corresponder a um propósito real, devendo ser utilizada, na perspectiva de Solé (1998), quando queremos comunicar algo aos demais colegas ou quando, de acordo com Kleiman (2001), pretendemos realizar uma apreciação estética da linguagem.

Nesse sentido, faz-se necessário que haja um olhar reflexivo do professor, de forma questionar a própria prática e buscar, se necessário, respaldo teórico para justificar e compreender seu trabalho em sala de aula, com relação ao ensino da leitura e às habilidades e competências trabalhadas. A educação continuada, reflexiva, questionadora e crítica do professor torna-se fundamental para que a escola, comprometida com a formação leitora do aluno, na tentativa de acertar, não se distancie da sua verdadeira função, afastando, consequentemente, o aluno de qualquer tipo de leitura, conforme pontua Zilberman (2013).

\section{Considerações Finais}


O trabalho com leitura em sala de aula não é uma tarefa fácil e apresenta muitos desafios para o professor quando se trata da realização de uma prática significativa e relevante para o aluno, em que se busca despertar o interesse pela leitura e formar um competente leitor crítico e reflexivo do mundo ao seu redor. Ao priorizar uma formação mais contemporânea, proposta pela literatura da área e pelos documentos oficiais, é fundamental que o professor esteja respaldado teoricamente para agir de maneira fundamentada e coerente com uma perspectiva de leitura dinâmica e interativa, que se realiza por meio da interação entre texto e leitor (aluno).

Não se pode atribuir ao trabalho com a oralização em sala de aula o desenvolvimento de habilidade e competência que não lhes competem. Embora necessário e fundamental em sala de aula, este tipo de leitura não implica o trabalho com a compreensão do texto, pelo contrário, a depender de como e em que proporção ela é realizada e contemplada pelo professor, pode caminhar na contramão de uma formação que priorize a negociação e a construção de sentido e que objetive motivar e despertar o aluno para o ato e importância da leitura. Nessa pesquisa, pudemos verificar que a leitura em voz alta tinha lugar de destaque e essa prática era direcionada pela crença na leitura como oralização e como formação de hábito e no papel do professor como responsável tanto por contemplar uma diversidade textual, de forma a estimular o aluno a gostar de um segmento textual, quanto por solicitar a pesquisa e a leitura de textos diversos em voz alta.

Entendemos que a formação do professor, para a realização do trabalho de leitura em sala de aula, deve vir acompanhada também de uma prática conscientizadora e reflexiva (PIMENTA; GHEDIN, 2002; ZEICHNER, 2008). Há necessidade de que o professor tenha consciência sobre suas próprias crenças acerca do processo de ensinar e aprender língua portuguesa e, mais especificamente, sobre o ensino de leitura, tendo em vista que, conforme apontam as pesquisas na área (BARCELOS, 2006), as crenças influenciam a prática do professor em sala de aula e também podem ser influenciadas por elas, em um processo bidirecional. O respaldo teórico e a consciência do professor sobre suas próprias crenças, que direcionam procedimentos em sala de aula, são fundamentais para compreender por que esse profissional trabalha da maneira como trabalha, quais são as habilidades e competências contempladas por meio dos procedimentos realizados e que tipo de leitor ele quer formar e realmente está formando.

\section{Referências}


BAKHTIN, M. Estética da criação verbal. 3.ed. Rio de Janeiro: Forense Universitária.

BARCELOS, A. M. F. Crenças sobre aprendizagem de línguas, linguística aplicada e ensino de línguas. Linguagem \& Ensino (UCPel), Pelotas - RS, v. 7, n.1, p. 123-156, 2004. Disponível em:<http://www.revistas.ucpel.tche.br/index.php/rle/article/view/217/184>. Acesso em: maio 2014.

Cognição de professores e alunos: tendências recentes na pesquisa de crenças sobre ensino e aprendizagem de línguas. In: BARCELOS, A. M. F; VIEIRA-ABRAHÃO, M. H. (Orgs). Crenças e Ensino de Línguas: Foco no professor, no aluno e na formação de professores. Campinas, SP: Pontes Editores, 2006, p. 15-42.

Reflexões acerca da mudança de crenças sobre ensino e aprendizagem de línguas. Revista Brasileira de Linguística Aplicada, v. 7, n. 2, p. 109-138, 2007. Disponível em: <http://www.scielo.br/pdf/rbla/v7n2/06.pdf>. Acesso em: maio 2014.

; MORAES, R. B. Beliefs and Emotions in Action Logs of Futures English Teachers. In: Afetividade e emoções no ensino/aprendizagem de Línguas: múltiplos olhares. Campinas: Pontes, 2011.

BRASIL, MEC. SEF. Parâmetros Curriculares Nacionais: primeiro e segundo ciclos do Ensino Fundamental. Língua Portuguesa. Brasília, 1997. Disponível em: <http://portal.mec.gov.br/seb/arquivos/pdf/livro01.pdf>. Acesso em: fev 2014.

BREVES FILHO, J. S. Uma proposta de leitura. In: __. Pelos túneis do texto: tecendo uma proposta de leitura. Imperatriz/MA: Ética, 1996, p. 80-90.

GRANVILLE, M. A. (Org.). Sala de aula: ensino e aprendizagem. Campinas: Papirus, 2008.

LEAL, T. F.; MELO, K. R. Planejamento do ensino da leitura: a finalidade em primeiro lugar. Práticas de leitura no ensino fundamental. In: BARBOSA, M. L. F. F. e SOUZA, I. V. (Org.). Belo Horizonte: Autêntica, 2006.

KLEIMAN, A. A concepção escolar de leitura. In: . Oficina de leitura: Teoria e Prática, ed.10. Campinas: Pontes, 2001, p.15-30.

O conhecimento prévio na leitura. In: Texto e leitor: aspectos cognitivos da leitura. Campinas: Pontes, 2004a, p.13-27.

Objetivos e expectativas de leitura. In: Texto e leitor: aspectos cognitivos da leitura. Campinas, Pontes, 2004b, p.29-44.

MARCUSCHI, L. A. Compreensão de texto: algumas reflexões. In: DIONÍSIO, A. P.; BEZERRA, M. A. (Org). 3ed. O livro didático de Português: múltiplos olhares. Rio de Janeiro: Lucerna, 2005.

PIMENTA, S. G. Professor Reflexivo: construindo uma crítica. In: PIMENTA, S. G.; GHEDIN, E. Professor Reflexivo no Brasil: gênese e crítica de um conceito. São Paulo: Cortez Editora, 2002. 
; GHEDIN, E. (Orgs). Professor Reflexivo no Brasil: gênese e crítica de um conceito. São Paulo: Cortez Editora, 2002.

ROJO, R. Letramentos Múltiplos, escola e inclusão social. São Paulo: Parábola, 2009.

SANTOS, C. F.; MENDONÇA, M. e CAVALCANTE, M. C. B. Trabalhar com texto é trabalhar com gênero? In: __ ; SANTOS, C. F. e CAVALCANTE, M. C. B. (org). Diversidade Textual: os gêneros na sala de aula. Belo Horizonte: Autêntica, 2007.

SAVELI, E. L. Leitura na escola: as representações e práticas de professoras. Curitiba: Fortum Granchelli/Moderna, 2003.

SCHON, D. The Reflective Practitioner. New York: Basic Books, 1983.

SOARES, M. Alfabetização e Letramento: caminhos e descaminhos. Pátio, n. 29 fev/abril, 2004. Disponível em: <http://www.scribd.com/doc/18892732/ArtigoAlfabetizacao-eLetramento-Magda-Soares1>. Acesso em: set 2015.

SOLÉ, I. Estratégias de leitura. Porto Alegre: Artes Médicas, 1998.

SILVA, K. A. Crenças sobre o ensino e aprendizagem de línguas na Lingüística Aplicada: um panorama histórico dos estudos realizados no contexto brasileiro. Linguagem \& Ensino, v.10,n.1,p.235-271,jan./jun.2007.

VYGOTSKY, L. V. Pensamento e Linguagem. Tradução de Jefferson Luiz Camargo. São Paulo: Martins Fontes, 1987.

. A construção do pensamento e da linguagem. Tradução de Paulo Bezerra. 2. ed. São Paulo: WMF Martins Fontes, 2010

ZEICHNER, K. M.; LISTON, D. P. Understanding Reflective Teaching. In: Reflective Teaching: An Introduction. New Jersey: Lawrence Erlbaum Associates Publishers, 1996.

ZEICHNER, K. M. Educating Reflective Teacher for Learner Centered-Education

Possibilites and Contradictions. In: GIMENEZ, T. (org.). Ensinando e Aprendendo Inglês na Universidade: Formação de Professor em Tempos de Mudança. Londrina: ABRAPUI, 2003.

ZEICHNER, K. M. Uma análise crítica sobre a —reflexão como conceito estruturante na formação docente. Revista Educação e Sociedade, Campinas, v. 29, n. 13, p. 535-554, maio/ago 2008.

ZILBERMAN, R. Porque a leitura da literatura na escola. In: GERHARDT, A. F. L. M.; AMORIM, M. A. de; CARVALHO, A. M. (Org.). Linguística aplicada e ensino: língua e literatura. Campinas: Pontes, 2013. 